\title{
Research on the Supply-Side Market Conditions of Agricultural Insurance of Sichuan and the Corre- sponding Countermeasures
}

\author{
Shanxiang Liang, Dongchuan Lin*, Miao Xu, Ruijie Lu and Qi Tang \\ Sichuan Agricultural University, Business School, Chengdu, 611830 \\ ${ }^{*}$ Corresponding author
}

\begin{abstract}
Under the background of the implementation of the Rural Revitalization Strategy proposed in the report of the 19th National Congress of CPC, with regard to the unbalanced and insufficient development on both agriculture and village sides, this paper firstly acquire the current situation and existing problems of Sichuan agricultural insurance and then analyze its causes. Finally, we put forward the suitable supply-side structural reform strategy for agricultural insurance innovation from four aspects: governmental support, credit system construction, supply capacity construction of insurance agent and insurance business innovation.
\end{abstract}

Keywords-agricultural insurance; supply enthusiasm; supply ability; business innovation

\section{INTRODUCTION}

Agriculture is the foundation of the national economy and plays an essential role in the layout of national economic. The government has always attached great importance to the development of agricultural in our country. By 2017, the document No. 1 of the Central Government has consecutively been focusing on the issue of "Three Rural Issues" for 14 years. In 2017, the 19th National Congress of the Communist Party of China was held successfully. The Central Committee put forward the idea of the Strategy of Rural Revitalization and gave priority to the development of agriculture and rural areas. Agricultural insurance plays an important role in spreading agricultural risks, compensating for peasants' losses, improving agricultural comprehensive productivity and increasing farmers' income.

However, the reality of agricultural insurance in China is not optimistic, showing the problem of single type, systemic risk, asymmetric information, positive externalities, high payout rate, high risk, and so on. The imbalance between supply and demand of agricultural insurance in China has become increasingly prominent. With the further promotion of the agricultural supply-side structural reform, the demand for agricultural insurance in modern agricultural development is more intense. Therefore, it is necessary to speed up the development of demand-oriented agricultural insurance and raise the level of support and indemnity for agricultural insurance.

Sichuan, as a major agricultural province, with the continuous supply-side reform of agriculture, its agricultural insurance will develop to be a modernized one. The development and exploitation of new agricultural insurance types will con- stantly be put forward to meet the needs of agricultural modernization. Agricultural insurance will be known and more valued by more and more people. Therefore, studying the innovation of agricultural insurance in the agricultural supply-side structural reform contributes to the coordinated development of agricultural insurance, agricultural industrialization and rural development.

\section{CURRENT STATUS OF AGRICULTURAL IN- SURANCE SUPPLY}

\section{A. Insurance Institutions}

By the end of the 2016, there were 37 insurance institutions in Sichuan Province but only 11 engaged in agricultural insurance, accounting for $29.7 \%$, dominated by the People's Insurance Company of China (PICC). In 2016, the agricultural premium income of Sichuan was 41712.14 million RMB, of which PICC agricultural premium income reached 25,223.24 million RMB, with a proportion of $60.47 \%$, much higher than that of other companies.

PICC is the first insurance company in new China. As early as 1951, the Sichuan Branch of PICC tried to run agricultural insurance such as cattle, pigs, cotton and rice. Since the introduction of the pilot schemes of central policy agricultural insurance in 2007, PICC has always played an important role in the development of agricultural insurance in Sichuan Province. In 2007, PICC took the lead in undertaking the produce of fattening pigs, rice and corn in Ziyang, a typical agriculture-dominant city of Sichuan. After years of development, it covers almost all kinds of agricultural insurance in Sichuan, including rice, corn, wheat, and so on. Sichuan has become a province with the largest scale of PICC's business, its premium of agricultural insurance accounts for one sixth of the overall business of PICC Branch of Sichuan Province, and agricultural insurance has become the third largest product line of PICC.

\section{B. Agricultural Insurance Coverage}

As a major economic province in the west and a dominant agricultural province in China, Sichuan Province started running agricultural insurance early and the agricultural insurance there developed rapidly. In early 1950, when first founding the new China's insurance industry, livestock insurance business has been piloted in Sichuan. In 1982, Sichuan became the first province in the country to pilot the cattle insurance, cow insurance, crop insurance, and so on. And then in 2004, Sichuan 
became the first pilot province of agricultural insurance. By 2017, agricultural insurance products in Sichuan have covered farming, forestry, fishing and animal husbandry, almost all of the planting and aquaculture industries.

\section{Financial and Policy Support}

In 2007, the central government decided to subsidize agricultural insurance premiums, and there were 12 agricultural insurance with the subsidy in 2015. In terms of subsidies for agricultural insurance, Sichuan Province actively optimized the share of premiums and effectively reduced the burden on peasants, and has set up a subsidy mechanism for agricultural insurance jointly financed by the central, provincial, municipal and county governments. Taking agricultural insurance of Chengdu in 2016 as an example, under the co-support of the four-level finance, farmers in Chengdu borne $10 \%$ to $25 \%$ of the premiums, effectively reducing the farmers' economic pressure, arousing their enthusiasm in insurance and promoting the rapid development of agricultural insurance in Chengdu. In addition, except for the central government, the municipal and county governments also have vigorously subsidized agricultural insurance and achieved good results. For example, Dujiangyan launched the kiwifruit agricultural insurance business and Jintang County is subsidized by the municipal and county governments for special insurance such as the price insurance index of live pigs and edible fungi.

\section{EXISTING PROBLEMS}

\section{A. Imbalanced Development in Insurance Companies}

It's imbalanced to the development of 11 agricultural insurance companies in Sichuan Province, showing that the development of the PICC is much better than that of other insurance companies. In 2015, the annual premium income of PICC was 1783.31 million RMB, 548.98 million higher than the second rank, AVIC Property Insurance Co., Ltd. In addition, the agricultural insurance claims more than other insurances, such as enterprise property insurance, accident insurance and life insurance, which makes many insurance companies unwilling to engage in agricultural insurance business. However, agriculture belongs to the weak industry, so it's prone to appear catastrophe risk, and cause high loss rate.

\section{B. Imperfection of the Governmental Subsidy Policy}

Although Sichuan Province has a good performance in subsidies for agricultural insurance, it still lacks coordination with its basic agricultural status. Firstly, the government's agricultural insurance is subsidized in a single way, only giving priority to the single premium subsidies, Therefore, except the 12 kinds of agricultural insurances which are subsided by the central authority, all the others in Sichuan Province are subsided by the provincial, municipal and county finance. Second, the coverage of financial subsidies is small, and most of them still remain in the pilot stage. For instance, the price insurance subsidy for pig, yak and Tibetan sheep is still in the pilot stage, while the output insurance and meteorological index insurance are still under exploration. In addition, the continuing instability of insurance policy also suppresses insurance companies ' supply.

\section{Low Depth Agricultural Insurance}

Although the scale of agricultural insurance in Sichuan ranks among the top in the country and occupies a certain share of the property insurance in the province, it is still underdeveloped in the overall insurance market. The depth of agricultural insurance in Sichuan Province is still at a low level. From 2011 to 2014, the insurance depth has been growing, but still not high. From 2015-2016, the insurance depth showed a downward trend, and it fell to 0.00842 in 2016 . Compared with the depth of property insurance, there is a huge gap between them in 2013, the depth of agricultural insurance accounted for only $0.81 \%$ of that of the property insurance, and in 2016 it declined to $0.65 \%$. It can be seen that agricultural insurance contributes very little to the agricultural economy development of Sichuan Province and the status of agricultural insurance in the national economy is still not high.

\section{Imperfect Legal Mechanism}

There are no specific laws and regulations about agricultural insurance in China, just some general rules in the insurance law. Although the "Insurance Regulations for Agriculture" was promulgated in 2012, the regulations mainly made specific provisions for insurance institutions, but few explicit provisions on the government and peasants, which will make the government lacks supervision, peasants lie for the premiums and other issues in the development process of agricultural insurance. In 2004, Sichuan Province formulated the "Opinions on Developing Agricultural Insurance in Sichuan Province" and then in 2017, Sichuan Province promulgated the "Administrative Measures on Subsidy for Agricultural Insurance in Sichuan Province" on the basis of the insurance regulations. These regulations have actively promoted the development of agricultural insurance, but there are no clear regulations on government duties, supporting measures, and supervision. On the other hand, the catastrophe risk diversification mechanism and the risk assessment mechanism are not perfect. Agriculture is a high-risk industry and once the risk occurs, it will be paid out entirely by the insurance institutions, increasing the redress rate of the insurance company.

\section{CAUSES ANALYSIS OF THE EXISTING PROB-} LEM

\section{A. Frequency Natural Disasters and Increased Cost of Agri- cultural Insurance}

The frequent occurrence of natural disasters such as floods and droughts in Sichuan has increased the cost of insurance companies and the rate of insurance companies' compensation. When large-scale agricultural catastrophe occurs, the insurance company will be hit with a fatal blow, suffering serious losses and not being able to sustain healthy development. The low economic benefits of agricultural insurance make many insurance companies unwilling to carry out agriculture insurance. Even if they carry out agricultural insurance business, they will tend to the agricultural insurance with lower risk or the government's subsidy. In a word, the four high characteristics of high risk, high cost, high rate and high compensation have made the insurance company less willing to carry out the agricultural insurance business. 


\section{B. Serious Problem of Information Asymmetry}

The information asymmetry in the insurance market is mainly reflected in moral hazard and adverse selection. Due to the lagging construction of rural credit system, it is difficult for the insurance institutions to obtain sufficient information about farmers and agriculture. Farmers are inclined to insure the insurance which is benefit to them, such as the poor land which is particularly vulnerable to disaster crops and low production. When agricultural disasters occur, farmers will be overly dependent on insurance and lack of precautions, increasing the rate of insurance companies' compensation. The disadvantages of moral hazard and adverse selection to insurance companies are high information, regulatory and indemnity expenses, which leads to the increase of insurance company's operating costs and the reduction of the supply capacity of agricultural insurance.

\section{COUNTERMEASURES AND SUGGESTIONS}

\section{A. Strengthen Government Support}

The government should strengthen financial support for agricultural insurance and promote the system of agricultural insurance subsidy. The 19th National Congress proposed to extend the contractual rights of the land for another 30 years, which is more conducive to the transfer of land management right to professional investors and cooperatives, and operation in scale. Therefore, the government should regard these professional investors as the key subsidy objects and make the financial subsidies more efficient. The construction of diversified subsidies will continue to subsidize farmers, at the same time strengthen the support for insurance companies in policy, expand the scope of concessions, establish compensation fund for agricultural insurance risks, diversified risk diversification mechanism and risk assessment mechanism, improve the insurance institutions' motivation to expand agricultural insurance business. In addition, the government should establish relevant regulations and formulate specific laws and regulations for agricultural insurance. Only under the premise of legal protection, can the development of agricultural insurance be effectively guaranteed, in this way, further promote the development of agricultural insurance.

\section{B. Speed up the Construction of the Rural Credit System}

In January 2018, Chengdu was approved as the first demonstration city in the construction of social credit system in China. Sichuan should actively promote the experience of Chengdu, improve the construction of rural credit system, set up a platform for rural credit data, standardize and legalize credit, and reduce information asymmetry. Guarantee funds and institutional building should be dominated by the government to encourage some commercial guarantee companies, which will provide warrant to farmer. Professional investors can also set up a mutual cooperation between guarantee agencies, so as to improve the supply willingness of insurance institutions. In addition, it is a guarantee for credit construction to strengthen the moral education of farmers, reduce adverse selection and moral hazard, improve agricultural science and technology and agricultural innovation ability, and enhance the ability to resist risks.

\section{Strengthen the Construction of the Supply Capacity of In- surance Companies}

Insurance company is the main body in the development of agricultural insurance business. First of all, insurance companies should improve the level of agricultural insurance business, performance timely and efficient compensation, improve the quality of agricultural insurance claims, and increase farmers' trust in agricultural insurance, as well as change the farmers' awareness of and attitude towards agricultural insurance. Second, insurance companies should strengthen the training of agricultural insurance professionals in insurance companies and improve their quality of personnel. Finally, insurance companies should actively expand the varieties of agricultural insurance, and adopt different insurance modes for agricultural professionals and retail investors, such as different premiums, differentiated development products, more options for farmers, in order to improve farmers' enthusiasm in insurance.

\section{Innovation of Agricultural Insurance Products}

In the innovation of agricultural insurance products, we should actively implement the structural reform on the supply side of agricultural insurance, develop products based on market demand, and develop preferential agricultural insurance. Take full account of the actual situation in the rural areas, and then implement different premium rates and piecewise premiums based on geographical differences and disaster-affected degree, adopt different ways from different space, time, and insured subjects to make the agricultural insurance coverage can be targeted to meet the needs of the mainly insured subjects. The insurance companies should actively expand the scope of agricultural insurance, such as actively carrying out the insurance of agricultural product prices. At present, Sichuan only implements price index insurance for vegetables and live pigs, and can also gradually develop into fruits, fisheries and other industries. Meanwhile, Sichuan can learn from other provinces' agricultural insurance modes, developing agricultural natural disaster index insurance and farmers' income insurance, and rely on green economic development to create agricultural products quality insurance.

\section{ACKNOWLEDGMENTS}

This paper is supported by the Scientific Research Project of Sichuan Provincial Education Committee (NO. 17SB0374), the key Research Project of Undergraduate Education and Teaching Reform of SICAU (NO. X2017023), and supported by the funding of the Discipline Construction and the Academic Team Construction program of SICAU.

\section{REFERENCE}

[1] Ning Wang. Analysis and Suggestions on "Double Cooler" Supply and Demand of Agricultural Insurance in Small-scale Farmers[J]. Cooperative Economy and Science and Technology, 2015 (11): 212.

[2] Yin-dong Li. Current Situation and Improvement of Agricultural Insurance in China[J]. Business, 2015(11): 195.

[3] Ying Zhao, Ting-ting Xie. Empirical Analysis on the Determinants of Farmers' Agricultural Insurance De-mand[J]. Land Reclamation Economy in Xinjiang, 2016(6): 371.

[4] Ya Qie. Research on Sustainable Development of Agricultural Insurance in China[D]. Hebei University of Economics, 2015: 35-38. 